\title{
Artes plásticas e educação ambiental: uma reflexão e sensibilização interdisciplinar.
}

\author{
Arts and environmental education: a reflection and interdisciplinary sensitizing \\ Jacira Dopcke dos Santos ', Mara Lúcia Didolich de Ávila², Margarete Inês Spillari Seidel², \\ Nádia da Costa ${ }^{4}$, Sandra Eliana Vasconcellos de Moura ${ }^{5}$.
}

\author{
${ }^{1}$ Pós Graduada em Letras - Universidade Regional do Noroeste do Estado do Rio Grande do Sul (UNIJUÍ) \\ ${ }^{2}$ Pós Graduada em Gestão Ambiental - Universidade Regional do Noroeste do Estado do Rio Grande do Sul (UNIJUÍ) \\ ${ }^{3}$ Pós Graduada em Artes Plásticas - Universidade Regional do Noroeste do Estado do Rio Grande do Sul (UNIJUÍ) \\ ${ }^{4}$ Licenciatura Plena em Artes Plásticas - Universidade Regional do Noroeste do Estado do Rio Grande do Sul (UNIJUÍ) \\ ${ }^{5}$ Pós Graduada em Pedagogia Gestora com Ênfase em Administração, Supervisão e Orientação Escolar - \\ Faculdade de Administração, Ciências, Educação e Letras (FACEL)
}

\begin{abstract}
Resumo
Este artigo apresenta, como ponto de partida, uma reflexão sobre conceitos trabalhados em Artes e Educação Ambiental. Também o desenvolvimento de atividades práticas e plásticas no processo educativo, considerando o papel do educador frente às aceleradas mudanças da sociedade, as relações pedagógicas e competências da situação de estudo, as quais exigem tanto dos educandos quanto dos professores mais dedicação e comprometimento. Trata-se de um projeto interdisciplinar que contempla as diferentes áreas do conhecimento: Artes, Educação Ambiental, Informática Educativa, Literatura e Ciências. Então, ao iniciar o ano letivo, houve a discussão e reflexão sobre a mensagem "A lição da borboleta", a qual despertou enorme curiosidade sobre o desenvolvimento e a vida desta. A partir desse interesse a elaboração do projeto e a construção de um borboletário para observação, e consequentemente diversas atividades nas diferentes áreas do saber. Dessa forma, um dos objetivos é buscar caminhos que possibilitem uma formação consistente e adequada aos discentes no processo educativo, a fim de que possam vislumbrar novas alternativas e possibilidades de conquistas no seu cotidiano.
\end{abstract}

Palavras-chaves: Educação ambiental. Pesquisa. Estética. Interdisciplinaridade.

\begin{abstract}
This article presents as a starting point, a reflection about the concepts worked in Arts and Environmental Education. And also the development of plastic and practical activities in the educative process, considering the educator's role that faces the fastest changes on society, the pedagogical relation and the competences on the study situation which demands from students as for the teachers more dedication and commitment. It discusses about an interdisciplinary project that approaches different areas of knowledge: Arts, Environmental Education, Computers in Education, Literature and Science. Then, when it started the school year there was a reflection and discussion about the message "The Lesson of the Butterfly", which aroused a huge curiosity in concern the development and its life. Whereof this interest is has been elaborated the project and construction from a butterfly vivarium to watch and consequently various activities in different areas of knowledge. As result, one of the objectives it is to search ways that possibility a consistent and adequate training to the educators on the educational process in order to have opportunity from daily achievements.
\end{abstract}

Keywords: Environmental education. Research. Appearance. Interdisciplinary. 


\section{INTRODUÇÃO}

As artes exprimem a identidade de um povo. Priorizar a expressão é oportunizar condições para o sujeito revelar o intelecto, sendo que a prática constante estimula a comunicação e a expressão estética. Além disso, encoraja e possibilita a independência do mesmo e, este sente-se capaz de realizar mudanças criativas em seu meio.

A Arte, como conhecimento, favorece a formação da identidade e a construção da cidadania. Assim, crianças e jovens vivenciam e compreendem a realidade. Consequentemente, são capazes de utilizar os problemas como desafios, modificar o social, opor-se ao conformismo, construir relações entre o mundo interior e exterior, ou seja, entre as emoções e o que é real, e ainda atuar eticamente no ambiente.

Assim sendo, o presente artigo propõe reflexões acerca das questões que permeiam a Arte. Também aprimorar, ainda que de modo geral, alguns pontos importantes: imaginação, percepção, sensibilidade, reflexão, criação e construção da poética pessoal. Além do desenvolvimento do pensamento artístico: leitura, fruição, bem como estimular o aluno a investigar, inventar e explorar a expressividade e a criatividade, tornando-o, dessa forma, um indivíduo mais sensível às belezas que o cercam. E, nesse processo de elaboração e construção das atividades, as crianças traduzirem e expressarem sua forma de ver, sentir e estar no mundo.

Vale ressaltar a importância da presença da Arte na vida do homem, por cumprir o papel de sensibilizar, libertar, dar prazer e despertar o olhar estético, pois ela é indispensável para o desenvolvimento humano, dentro ou fora do espaço educativo, possibilitando ao aluno refletir, dialogar e agir de forma organizada e coerente no mundo. Sabe-se da preocupação das sociedades, de modo geral com as questões do ambiente, porém, neste projeto, não é pretensão mudar a forma de ensino, mas deixar uma sementinha de inquietação, sensibilidade e reflexão no coração da criança, para que germine agora, em um futuro próximo, daqui a muitos anos, ou ainda não germine... na busca sensível e inteligente pela preservação do planeta.

"A educação ambiental é um componente essencial e permanente da educação nacional, devendo estar presente, de forma articulada, em todos os níveis e modalidades do processo educativo, em caráter formal e não formal" (art.1 $1^{\circ}$ e $2^{\circ}$, Lei Federal no 9.795, de 27/4/99).

Dessa forma, são dois os objetivos da presente reflexão. O primeiro é proporcionar aos educandos momentos nos quais estes vivenciem experiências estéticas, relacionadas à Arte. O senso estético é um modo contínuo e eficaz de compreender o mundo e agir sobre ele. Isso se faz através de atividades significativas, considerando a educação como pilar para o desenvolvimento das potencialidades do ser humano e a sua preparação à cidadania e o trabalho. E o segundo, é orientar as crianças a fim de que percebam a necessidade de preservação do ambiente e com isso sintam-se protagonistas de suas vidas, permitindo-lhes estabelecer novas relações consigo e o cuidado do lugar em que estão inseridas.

$\mathrm{E}$, conforme o cacique indígena norte americano Seatles, através de uma carta enviada ao presidente dos Estados Unidos: "À Terra não pertence ao homem; o homem é que pertence a Terra. Todas as coisas estão interligadas como o sangue que une a família.... O que ocorre com a terra recairá sobre os filhos da Terra. O homem não tramou o tecido da vida; ele é simplesmente um de seus fios. Tudo que fizer ao tecido fará a si mesmo." (PEDRINI,1998, p.24).

Então, segundo Brito (2002), para tratar a educação como o estabelecimento de novos valores do ser humano em relação ao meio, é indispensável um trabalho de educação em questões ambientais. Entendendo que essa não é apenas um veículo que possibilite mudanças de valores, mas que se constitua em um importante instrumento, para se alcançar os direitos básicos da cidadania.

Por conseguinte, o grupo de alunos envolvido no projeto está matriculado em duas escolas da Rede Municipal de Ijuí, RS: a Escola Municipal Fundamental Joaquim Porto Villanova e a Escola Municipal Fundamental Tomé de Souza, além de um grupo da Educação Infantil (Pré-Escola) e outro grupo maior dos Anos Iniciais (do $1^{\circ}$ ao $5^{\circ}$ ano). O projeto foi realizado no período de 2013.

\section{METODOLOGIA}

O projeto pretende tecer uma aproximação teórico-metodológica entre a Arte, a Educação Ambiental e o cotidiano do educando, com suas experiências e realidade de vida. Este foi vivenciado 
em duas escolas públicas, as quais destacam em seu currículo a importância de usar os recursos naturais de forma sustentável.

"Ensinar não é transferir conhecimento, mas criar as possibilidades para a sua produção ou a sua construção" (Paulo freire,1996, p. 24 e 25).

Esse projeto efetivou-se nas aulas de Artes, Informática Educativa e Ciências. Os professores que participaram atuam com essas turmas em atividades diversificadas, substituindo os docentes regentes, enquanto estes planejam suas aulas Para efetivação das mesmas, houve o envolvimento de vários segmentos da escola: alunos, professores, direção e coordenação, pais e funcionários. Além disso, o projeto foi desenvolvido com a turma dos Anos Iniciais ( $5^{\circ}$ ano) na Escola Municipal Fundamental Joaquim Porto Villanova e na Escola Municipal Fundamental Tomé de Souza, a Educação Infantil (Pré-Escola) e as turmas de Anos Iniciais ( $1^{\circ}$ ao $4^{\circ}$ ano).

Os educandos vivenciaram, na prática, conceitos da Arte: a sensibilidade, a percepção, a consciência estética, a imaginação, a leitura de imagens, a emoção, a investigação e a reflexão como ferramentas para os conhecimentos artísticos e de educação ambiental. Realizaram diversas pinturas, desenhos, construções tridimensionais, observações, trabalharam com recorte e colagem. Construíram conhecimentos, valores, atitudes, posturas, habilidades e destrezas, as quais a Arte, imprescindivelmente; sustenta em todas as áreas da experiência estética.

No desenvolvimento das atividades houve a utilização de várias imagens e diversos livros. Além de um estudo dialógico no momento da observação, criação de situações práticas e questionamentos desafiantes. Também, formulações de conceitos e indagações, vídeos, textos, pesquisas, Literatura Infantil Virtual na Sala de Informática, as quais esclareceram aos educandos, tanto questões da Arte, como questões ambientais.

"Imaginar é mais importante do que saber, pois o conhecimento é limitado, enquanto a imaginação abarca o universo". (Albert Einstein).

Então, a pretensão do projeto é oportunizar aos educandos autonomia para que se tornem sujeitos criativos, flexíveis, motivados, éticos. E, principalmente, capazes de autodeterminar-se, assumindo responsabilidades e correndo riscos, ou seja, ressignificando o seu cotidiano.

O presente artigo apresenta um caráter descritivo. Além disso, pretende proporcionar ao leitor visão clara e simples sobre os assuntos abordados e as práticas realizadas.

\section{RESULTADOS E DISCUSSÕES}

O projeto é uma metodologia que trabalha a interdisciplinaridade, a pesquisa, a curiosidade, o interesse, o prazer da descoberta. Dessa forma, fascina e surpreende o educando ao mesmo tempo que contribui para novas reflexões.

"Os Projetos de Trabalho contribuem para uma ressignificação dos espaços de aprendizagens de tal forma que eles se voltem para a formação de sujeitos ativos, reflexivos e participantes." (HERNANDEZ, 1998)

Para iniciar o ano letivo, houve uma dinâmica com o texto "A lição da borboleta". A partir dele, a leitura, questionamentos e várias discussões sobre a mensagem. Isso, tanto por parte do professor como dos alunos. Em seguida, a construção de uma borboleta gigante e várias borboletas pequenas, com a retomada das palavras mágicas e as regras da turma. $\mathrm{O}$ trabalho foi exposto na parede da sala de aula, para as mesmas não serem esquecidas e sim aplicadas. Porém, esta mensagem surpreendeu por disseminar no aluno interesse não só pelas questões de boa convivência, mas especialmente sobre a transformação (metamorfose) da borboleta: o ovo, a lagarta, tempo de vida, alimentação, pupa, habitat... Assim, a partir das curiosidades, desejos e ricos questionamentos, ficou indispensável a elaboração de um projeto com inúmeras atividades teóricas e práticas, a fim de satisfazer a busca de conhecimento, pelos alunos.

Então, inserir a Educação Ambiental na escola, com conteúdo e práticas corriqueiras, possibilitam inúmeras ações sustentáveis, não só no ambiente escolar, mas em todo seu entorno. Segundo Guimarães (2001), através da Educação Ambiental, o aluno passa a entender a sua relação com o meio.

Conforme Freire, é imprescindível assumir o dever de lutar pelos princípios éticos como do respeito à vida dos seres humanos, à vida dos outros animais, à vida dos pássaros, à vida dos rios e das florestas. 


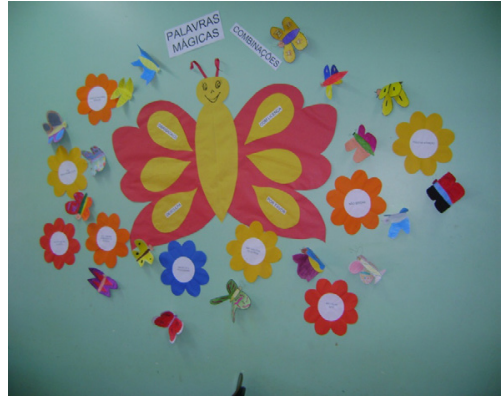

Figura 01

Figura 01, 02 - Painel construído com os alunos

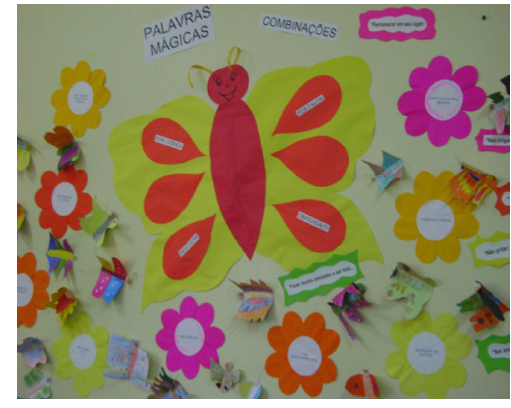

Figura 02

"Não creio na amorosidade entre homens e mulheres, se não nos tornamos capazes de amar o mundo. A ecologia ganha uma importância fundamental neste fim de século. Ela tem de estar presente em qualquer prática educativa de caráter radical, crítico ou libertador". (FREIRE, 2000, p 67).

Além disso, o momento atual, exige um Currículo, o qual promova uma formação de competência autônoma, crítica e criativa do educando. Dessa forma, o professor é aquele que possui a função de orientar, trabalhar e fazer trabalhar junto, que pesquisa e propõe aos educandos pesquisar e, por conseguinte, buscar respostas conjuntamente.

Nesse sentido, o professor é aquele que provoca, orienta, desafia, cria condições e situações, oferece subsídios para que o educando forme conceitos. Também organiza o ambiente, de tal maneira que o aluno se sinta motivado para aprender, para a descoberta, apostando na sua autonomia, desafiando-o a pensar. É o caso, por exemplo, do discente que vivencia a experiência de ver um casulo de inseto voador, abrindo-se para a vida, após ter passado longos dias fechado em seu pequeno mundo, que se rompe e liberta uma linda borboleta.

Este desafio, desde a observação e levantamento de hipóteses, até a conclusão, organiza o trabalho de outra forma. Quer dizer, com a participação ativa, as tarefas individuais e coletivas permitem, por meio da interação, a coleta de informações e dados para promover a sistematização e elaboração própria. Por isso, a pesquisa desperta o interesse de ambos: educando e educador, por ser um processo dinâmico, torna-se mais atraente.

Bagno (1998 p. 15) ressalta que, ensinar e aprender, então, é não apenas mostrar os caminhos, mas também orientar o aluno para que desenvolva um olhar crítico que lhe permita desviar-se das "bombas" e reconhecer em meio ao labirinto, as trilhas que conduzem às verdadeiras fontes de informação e conhecimento.

Assim, faz-se o caminho, e ao caminhar nada é pré-estabelecido. Entende-se que as verdadeiras fontes de informações e conhecimentos são aquelas em que os alunos buscam respostas às suas dúvidas: investigando.

E, as escolas da rede Municipal de Educação de Ijuí possuem o sistema operacional Linux Educacional, sistema este que é livre e pode ser baixado pela internet. Os laboratórios são equipados, com mais ou menos 10 máquinas, nas quais os alunos trabalham em grupos. Este projeto foi executado com a utilização do laboratório de informática das escolas citadas.

Para sanar dúvidas, aos questionamentos dos alunos, houve a busca de informações, através de pesquisas, acessando a internet, no Laboratório de Informática. Além de vários vídeos sobre a vida das borboletas, as curiosidades e características de cada etapa de desenvolvimento. Também, o auxílio do professor da área de Ciências (Biologia), a fim de dizimar dúvidas que surgiam. De posse das informações, aconteceu a construção de uma apresentação eletrônica, com base nos dados obtidos no decorrer do projeto.

Após a leitura do livro "A Borboleta Azul", disponível na internet pelo domínio público, surgiram diferentes ações: leitura de livro, em tela, com uso do multimídia; teatro, pintura através do computador; desenhos de borboletas, com programas específicos, bem como a pintura destes; digitação e produção de textos. Também a utilização do computador quanto às: atividades de salvar, abrir arquivos, selecionar, enfim, fazer uso das ferramentas adequadas para cada atividade desenvolvida. 
Então, o Laboratório de Informática é uma ferramenta que enriquece o trabalho de estudo e pesquisa, auxilia na construção da aprendizagem e do conhecimento, visto que, para a maioria dos alunos essa é uma prática dinâmica, prazerosa e muito esperada. Consequentemente, há a discussão com os pares, planejamento coletivo, e a inclusão das novas tecnologias às práticas escolares do cotidiano.

Segundo Manuel Castells (1999), em seu livro, "A Sociedade em Rede", um "excluído digital" tem três grandes formas de ser excluído. Primeiro, não tem acesso à rede de computadores. Segundo, tem acesso ao sistema de comunicação, mas com uma capacidade técnica muito baixa. Terceiro, (para mim é a mais importante forma de ser excluído e da que menos se fala) é estar conectado à rede e não saber qual o acesso que deve usar, qual a informação que deve pesquisar, como combinar uma informação com outra e como a utilizar para a vida. Esta é a mais grave porque amplia, aprofunda a exclusão mais séria de toda a História; é a exclusão da educação e da cultura porque o mundo digital se incrementa extraordinariamente.

Assim sendo, a primeira atividade foi a construção do borboletário. Organização deste com argila e fixação, no interior, de alguns galhos para que as lagartas tivessem um lugar especial para seus casulos.

Optou-se em estudar a borboleta-da-couve - Ascia-monuste.

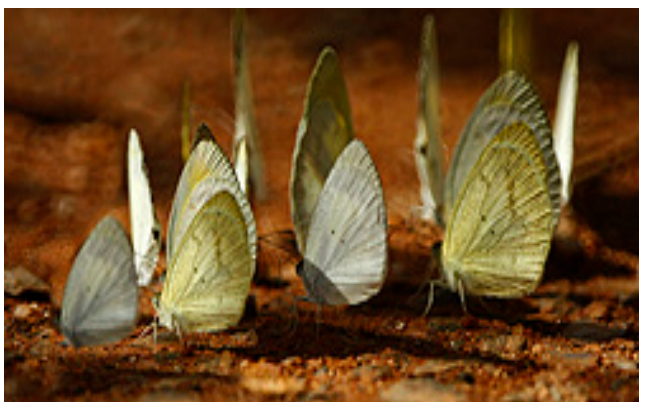

Figura 03 - Foto das borboletas estudadas.

Classe: Insecta - Ordem: Lepidoptera - Família: Pieridae

Espécie: Ascia monuste (Godart, 1818)

Biologia: A borboleta da couve é muito comum em todo o Brasil, alcançando até $6 \mathrm{~cm}$. De envergadura, pode ser observada mesmo nas ruas e jardins das cidades grandes. Essa espécie é considerada (praga) em algumas plantas cultivadas, principalmente da família Brassicaceae como couve, couve-flor e brócolis, onde as lagartas desfolham a planta. Tem como inimigos naturais pássaros, percevejos predadores e vespas predadoras. Na fase adulta, alimenta-se principalmente de néctar das flores. http://www.terrana.com.br/brasilanimal/LAGARTAS\%20 E\%20BORBOLETAS/index.html

O borboletário necessitava de cuidados. E, de dois em dois dias, era realizada a limpeza, a retirada, com delicadeza, dos galhos com a argila e as lagartas. Depois, reposto o papel toalha limpo com os galhos, as lagartas e as folhas de couve novas e frescas. Neste momento, os alunos observavam, com muita atenção, as mudanças que ocorriam. Havia anotações e discussão no grupo.

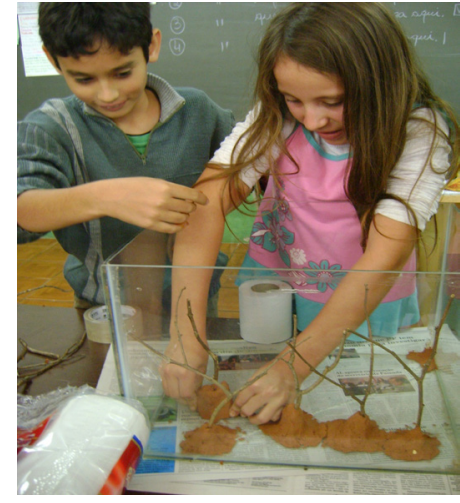

Figura 04

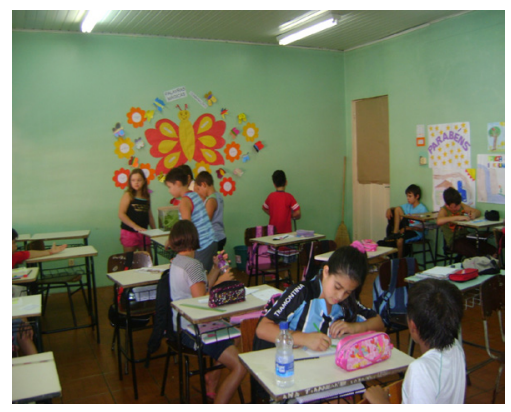

Figura 05

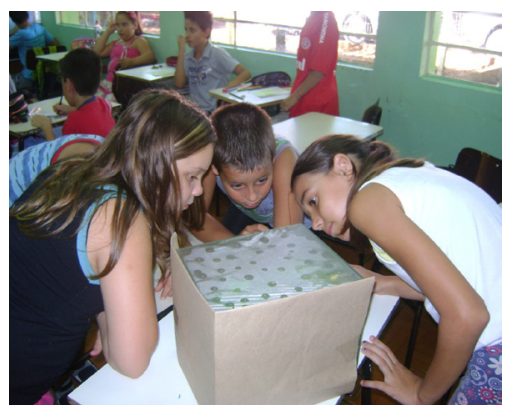

Figura 06

Figura 04,05,06 - Construindo o borboletário e Observação do borboletário 
Após muito comer, crescer e engordar, as lagartas começaram a diminuir o ritmo e os casulos iniciaram sua formação. Porém, pouquíssimas optaram por fazer os casulos nos galhos oferecidos e preferiram as paredes internas de vidro do borboletário. Houve reflexão entre discentes e professores e chegou-se à conclusão de que este era o lugar mais seguro para o desenvolvimento desta etapa.

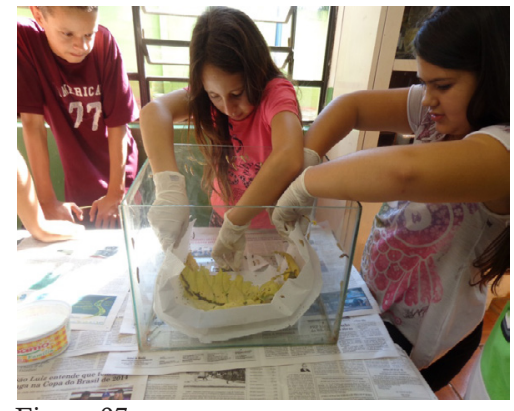

Figura 07

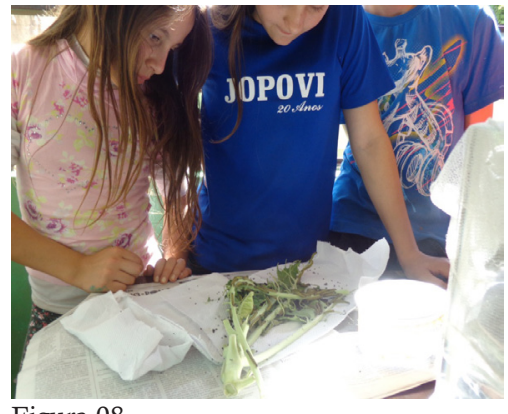

Figura 08

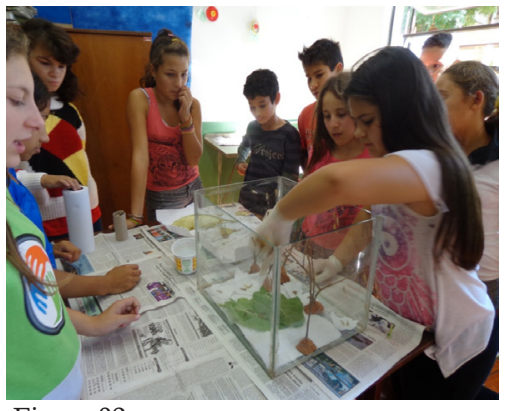

Figura 09

Figuras 07,08,09 - Observação e limpeza do borboletário com alimentação das borboletas.

Ao despertar para a vida, as borboletas encantaram os alunos. Estes ficaram maravilhados com as mesmas e as descobertas que se deram durante o processo.

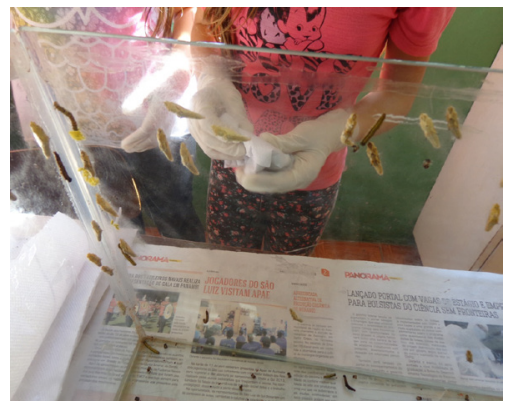

Figura 10

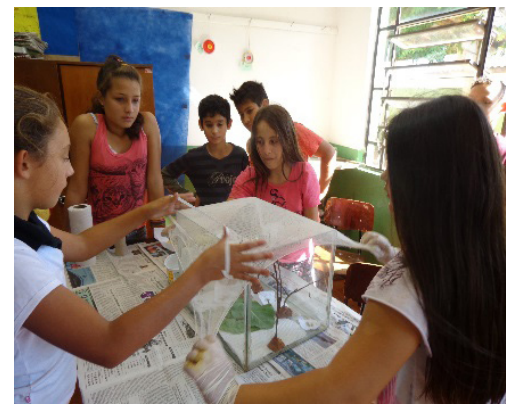

Figura 11

Figuras 10, 11 - Observação dos casulos e limpeza do borboletário.

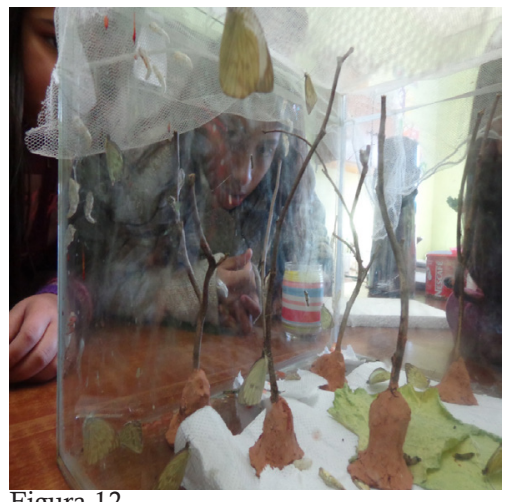

Figura 12

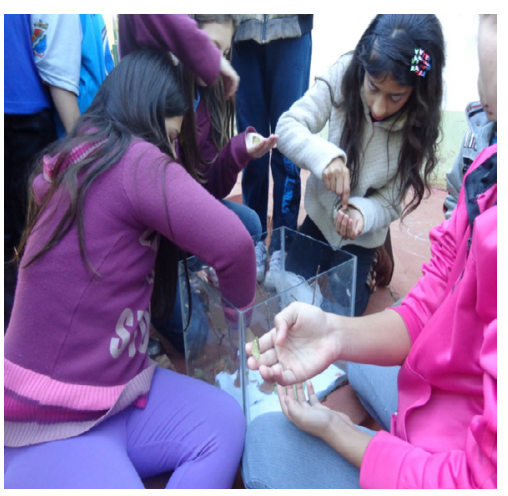

Figura 13
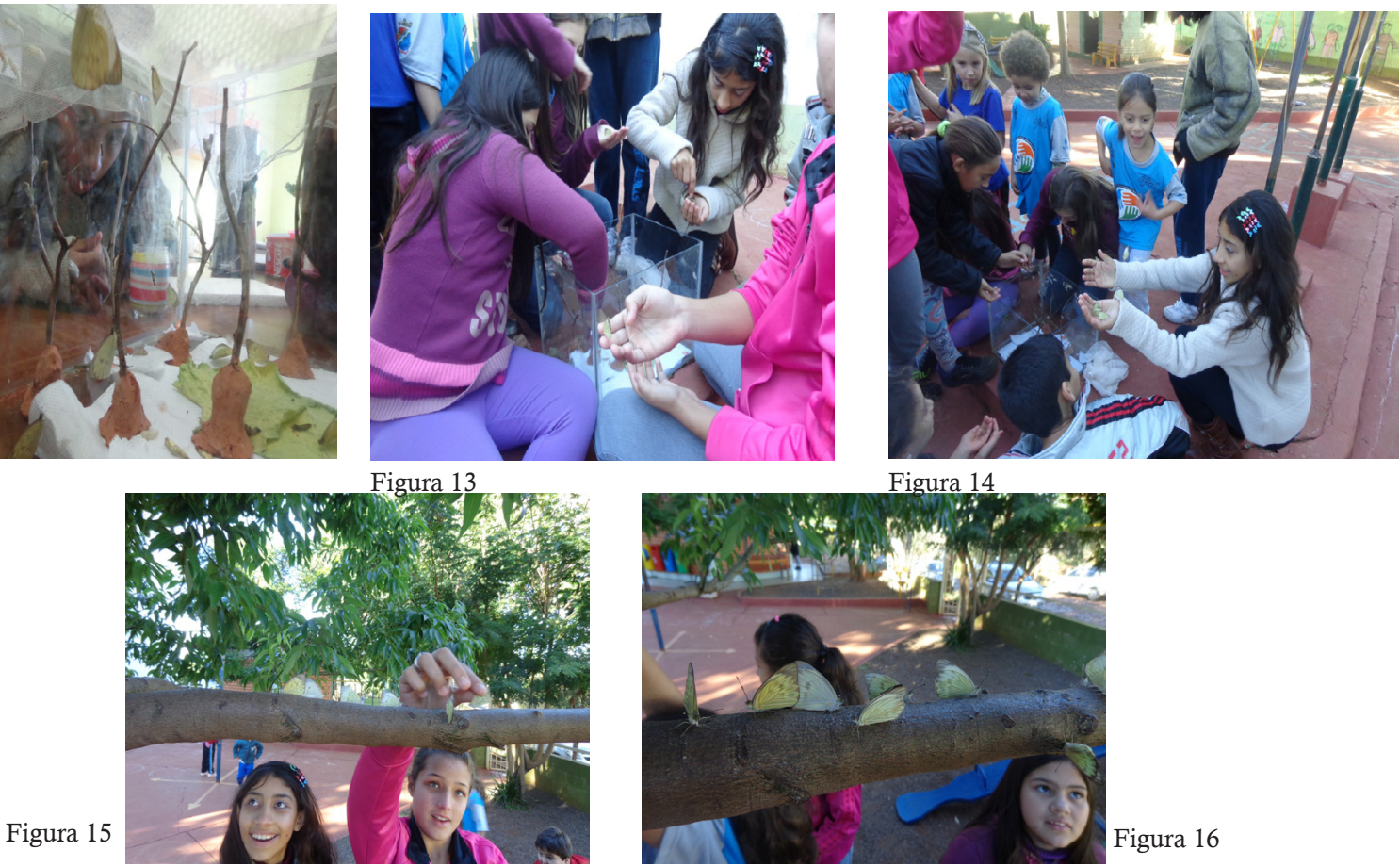

Figura 14

$$
\text { Figura } 16
$$

Figuras 12,13,14,15, 16 - Observação e voo das borboletas 
No decorrer do projeto, houve a construção de painéis, registro com desenho e pintura das fases de desenvolvimento da borboleta. A partir disso, os alunos construíram conhecimentos em Arte, a percepção estética, a expressão e a imaginação, aprimorando sua aprendizagem com relação às questões artísticas. Também perceberam pontos importantes sobre as formas, o espaço, os tamanhos, as cores e suas nuances. E, estimulados a buscar aprendizagens e a criar de maneira organizada, mas espontânea.

"Fazer arte reúne processos complexos em que a criança sintetiza diversos elementos de sua experiência. No processo de selecionar, interpretar e reformar, mostra como pensa, como sente e como vê. A criança representa na criação artística o que lhe interessa e o que ela domina, de acordo com seus estágios evolutivos. Uma obra de arte não é a representação de uma coisa, mas a representação da relação do artista com aquela coisa. [...] Quanto mais se avança na arte, mais se conhece e demonstra autoconfiança, independência, comunicação e adaptação social". (ALBINATI, 2009, p. 4).

\title{
Registro das fases da metamorfose da borboleta.
}

Ao longo dos estudos, nas pesquisas e cuidados com o borboletário, os alunos aprimoraram a sensibilidade com as questões da natureza, prestando mais atenção e preservando seu entorno. Assim, ao encontrar casulos, no pátio da escola, não os destruíam, chamavam para mostrar, ajudando a proteger os mesmos. Algo antes insignificante e corriqueiro, após os estudos tornou-se especial e significativo. Percebeu-se ainda uma maior proteção em relação ao ambiente de forma geral. O projeto foi importante para informar e consequentemente gerar mudanças comportamentais.

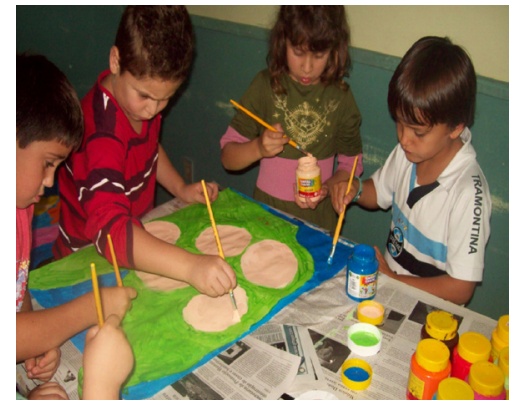

Figura 17 - Pintura: fase do ovo.

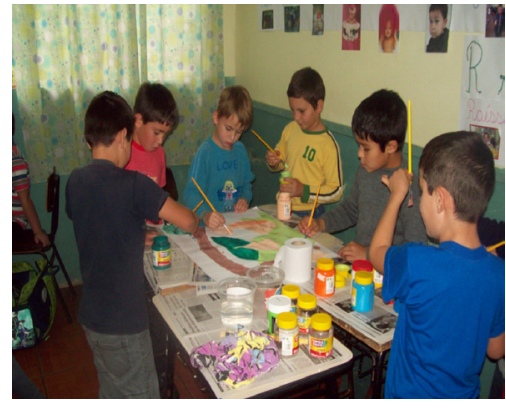

Figura 18 - Pintura: fase do casulo

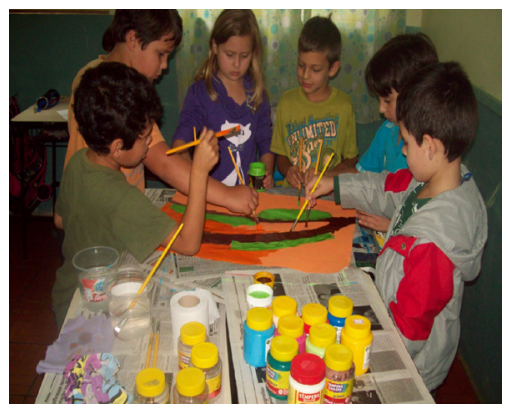

Figura 19 - Pintura: fase da lagarta.

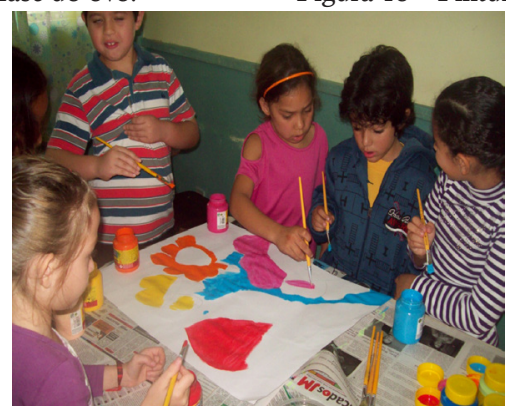

Figura 20 - Pintura: fase da borboleta.

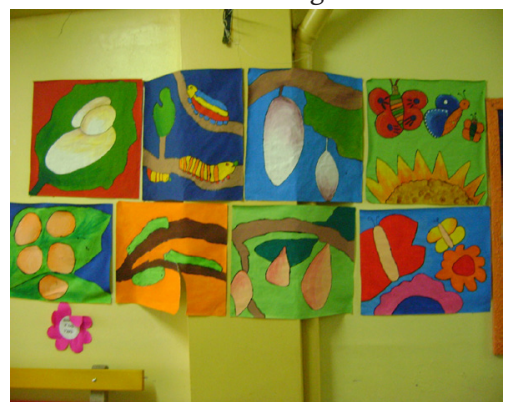

Figura 21 - Painéis em exposição.

Figuras 17,18,19,20,21 - Pintura das fases da metamorfose da borboleta.

\begin{abstract}
"A literatura infantil é, antes de tudo, literatura, ou melhor, é arte: fenômeno de criatividade que representa o mundo, o homem, a vida, através $d$ a palavra. Funde sonhos e a vida prática; o imaginário e o real; os ideais e sua possível/ impossível realização". (Cagneti,1996 p.7)
\end{abstract}

Para dar continuidade ao projeto, foi escolhida a literatura da escritora Ruth Rocha "ROMEU E JULIETA" Esse livro conta a história de duas borboletas, uma azul e uma amarela, que viviam no mesmo jardim, mas em canteiros diferentes, os quais eram separados por cores. Eram proibidas de conversar e brincar entre si, porque apresentavam cores diferentes. No decorrer da história, Romeu e Julieta fugiram de seus canteiros e foram aventurar-se. Mas escureceu e eles se perderam, por esse 

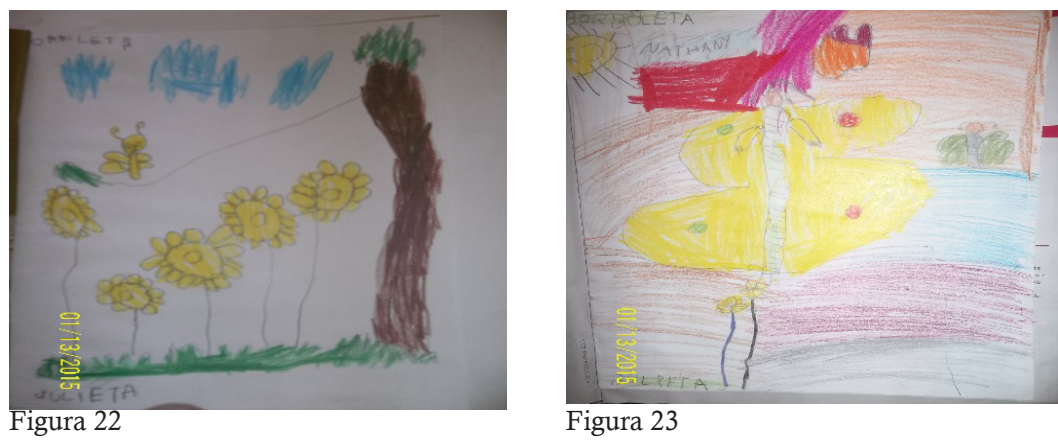

Figuras 22,23 - Desenhos dos alunos a partir da história

motivo seus pais tiveram de se unir e conversar para salvar seus filhos perdidos, mobilizando assim todas as borboletas de todos os canteiros e de todas as cores. Após encontrar Romeu e Julieta, a vida no jardim se transformou. Assim, poderiam sair de seus canteiros e passear no jardim com liberdade e sem preconceito de cor. A vida ficou mais harmoniosa, divertida e feliz.

Após a audição da história de Ruth Rocha, houve uma conversa sobre a relação dela com a vida de cada educando. Também as diferenças dos indivíduos, os quais vivem em lares distintos, convivem com outras pessoas, demonstram hábitos e valores diferentes e que podem conviver e respeitar-se mutuamente.

Além disso, os alunos manusearam o livro de Romeu e Julieta. Após, cada um registrou a borboleta que quisesse e na cor que desejasse com lápis de cor, em uma folha de desenho. Houve acabamento com cola colorida, gliter, recorte, colagem e montagem de um painel com as borboletas e flores coloridas.

"Como é gostoso e importante para a formação da criança ouvir histórias. Contá-las instigando a curiosidade e o desejo de "quero mais" expresso pelas crianças no "conta outra vez". São esses sentimentos que nos movem para conhecer e aprender as coisas que estão no mundo, e, sabendo-as registradas em livros, certamente iremos recorrer a eles, nos tornando assim, leitores por desejo e motivações." (Perrone e Lara, 2002, p.123)

Então, é importante o professor sensibilizar os educandos de forma prazerosa e fazê-los viajar e até querer ser um dos personagens da história. Além disso, a leitura proporciona lições de vida, resolução de problemas, desperta a criatividade, autonomia e criticidade, elementos importantes para o crescimento pessoal.

Para auxiliar na aprendizagem artística, através de observações e leituras de imagens, optouse pelas obras de Romero Britto, um famoso artista plástico brasileiro, nascido em Pernambuco, em 1963. Começou seu interesse pelas artes na infância, quando usava sucatas, papelões e jornais para exercitar sua criatividade. Suas obras deixam perceber claramente os elementos básicos da linguagem visual, como as linhas, planos de fundo, cores alegres, formas geométricas, texturas variadas e desenhos simples. Hoje, Romero está radicado em Miami, nos EUA, onde ficou conhecido pelo seu estilo alegre e colorido, e por apresentar a arte pop. É considerado um dos artistas mais prestigiados pelas celebridades americanas e é o pintor mais bem sucedido fora do Brasil.

Quanto à metodologia, primeiramente os alunos conheceram a biografia de Romero Britto e suas principais características, contextualização e apreciação de suas obras. Após, uma releitura da obra "BORBOLETA" com observações e reflexão sobre a mesma. Os desenhos foram espontâneos, e cada educando pode escolher o que desenhar e pintar com tinta guache, utilizando as cores alegres e formas simples do artista.

Em seguida, os alunos foram desafiados a construir uma literatura infantil. A partir da observação de exemplos e conversação, mostraram-se inteiramente motivados, principalmente quando a professora sugeriu trabalhar não com papel, mas com tecido. Primeiramente, houve a elaboração da história de forma coletiva. Cada turma criou sua história e posteriormente o seu livro. Neste momento, os discentes estavam empolgadíssimos, demonstrando até uma certa ansiedade e aflição para confeccioná-lo. 


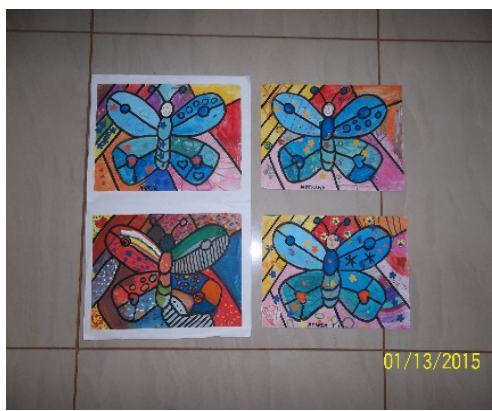

Figura 24

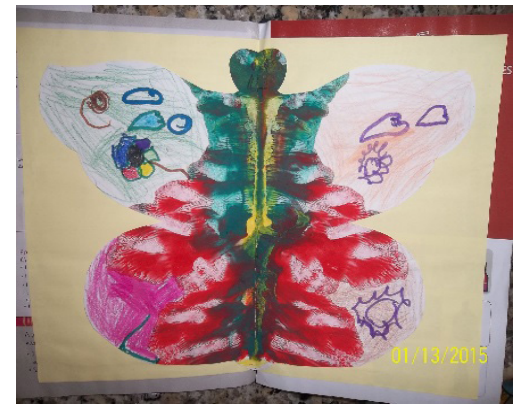

Figura 26

Figuras 24,25,26,27 - Releituras das obras de Romero Britto

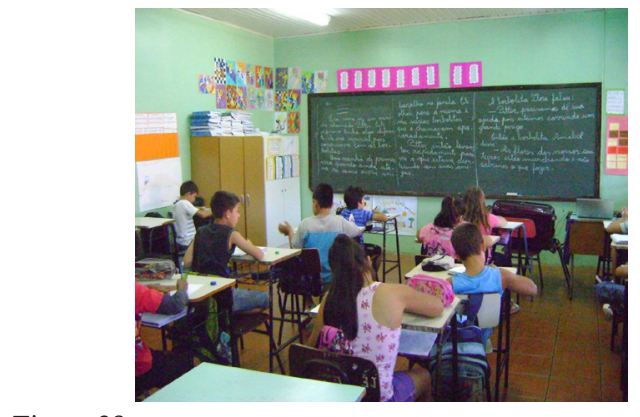

Figura 28

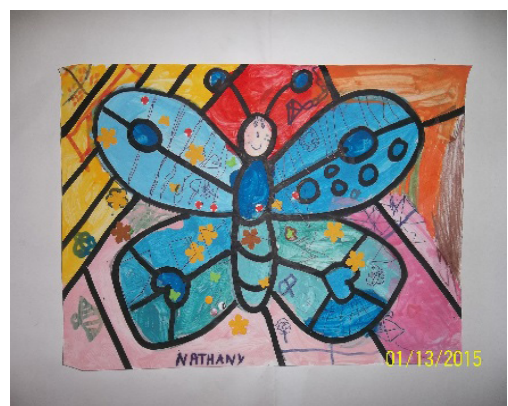

Figura 25

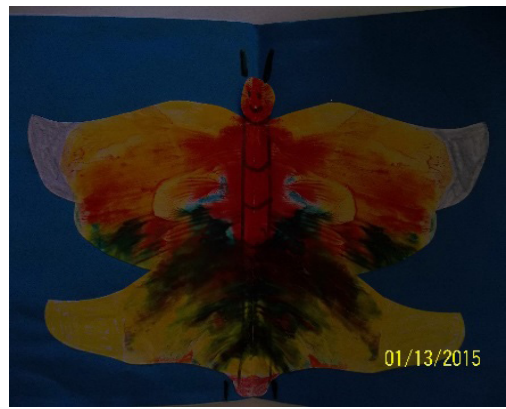

Figura 27

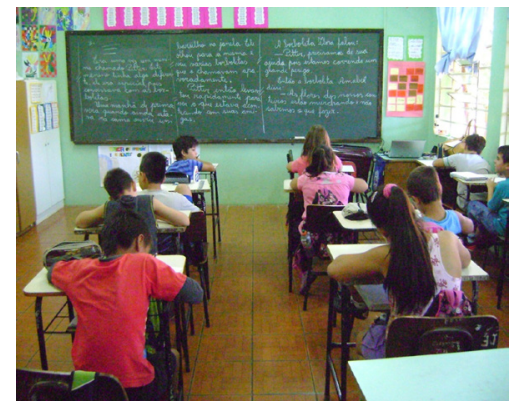

Figura 29

Figuras 28,29 - Cópia da história no caderno e a construção coletiva no quadro.

Após o texto pronto, cada turma elencou as imagens que seriam necessárias para a construção do livro. Deu-se início, à elaboração dos desenhos. Os alunos produziram várias formas sobre o mesmo tema. Através de pesquisa, leituras de imagens e observação de outras literaturas infantis, as crianças criaram os desenhos necessários para posterior montagem do livro.

"Compreender uma imagem implica em ver construtivamente a articulação de seus elementos, suas tonalidades, suas linhas e volumes. Enfim, apreciá-la, na sua pluralidade de sentidos, sejam imagens da arte erudita, popular, internacional ou local, sejam produções dos alunos, o meio ambiente local ou construído; imagens da televisão, informações visuais diversas presentes no cotidiano". (Barbosa, 2008, p.81).

Então, houve a divisão dos textos por páginas e a partir dos trabalhos dos alunos, a composição dos desenhos destas, na superfície do livro (tecido). Em seguida, o pano foi tingido pelos alunos com aguada de tinta de tecido, preparada anteriormente pela professora, para a elaboração do fundo das páginas. 


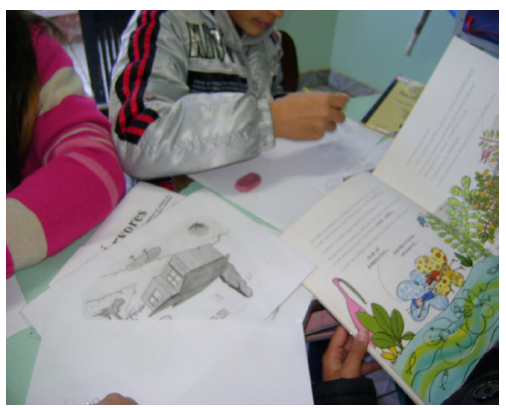

Figura 30

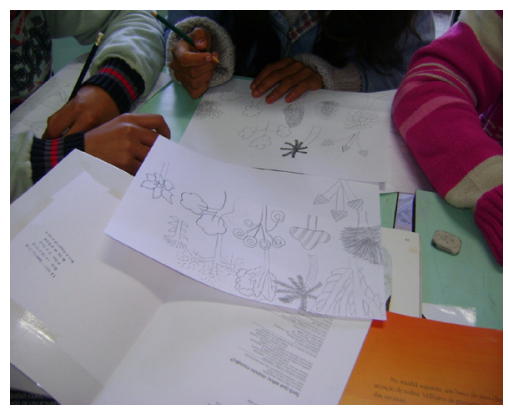

Figura 31

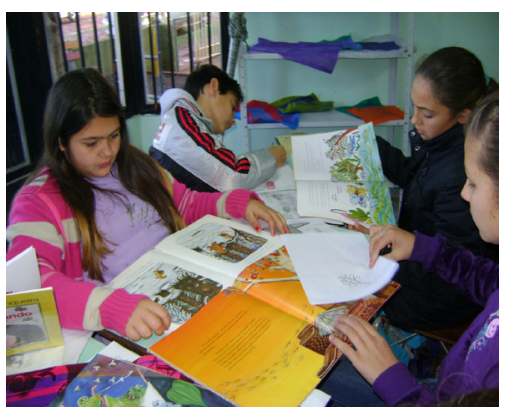

Figura 32

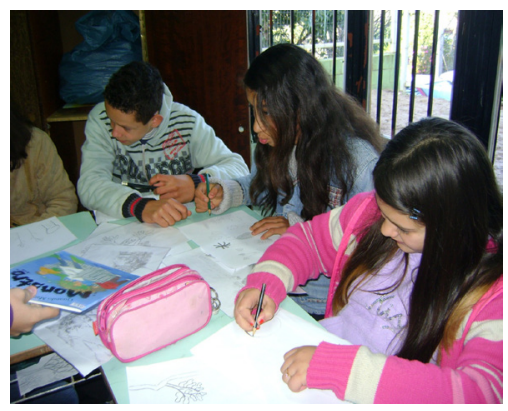

Figura 33

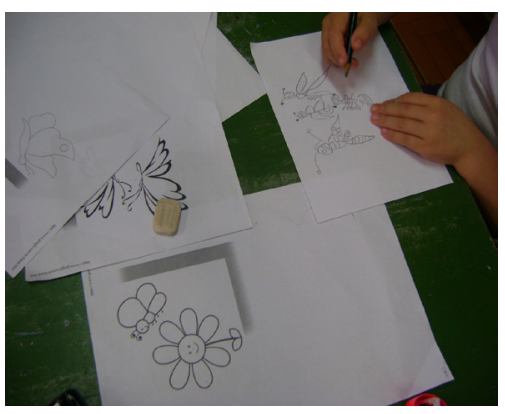

Figura 34

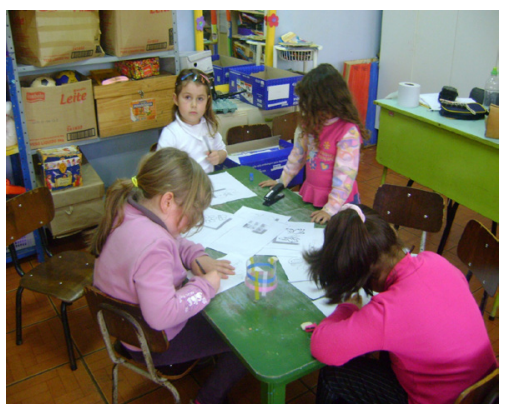

Figura 35

Figuras 30,31,32,33,34,35 - Pesquisa e elaboração das imagens para o livro

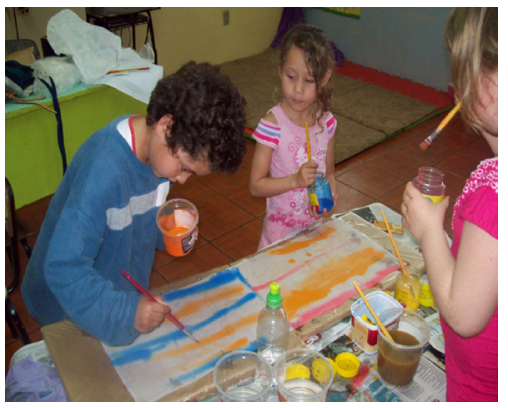

Figura 36

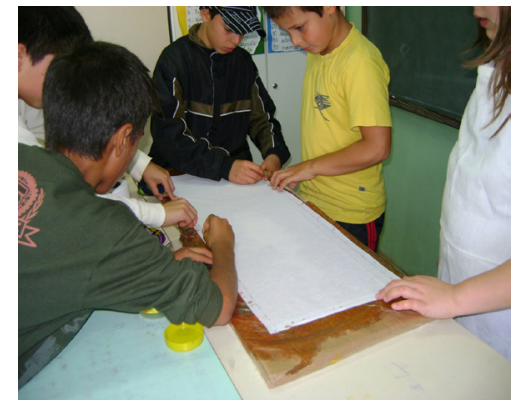

Figura 38

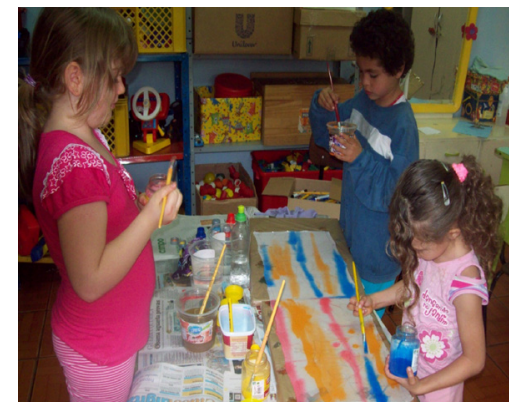

Figura 37

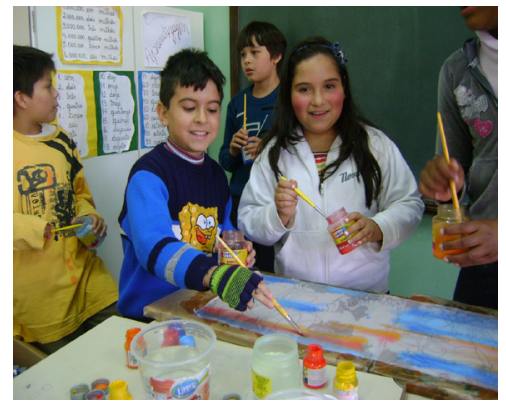

Figura 39

Figuras 36,37,38,39 - Pintura do fundo das páginas.

Com o fundo pronto, aconteceu, efetivamente, a pintura das imagens. Momento esse esperado com ansiedade e felicidade pelos educandos. Todos queriam muito pintar os desenhos, pois além de ser um trabalho criado por eles, havia o material (tecido e tinta de tecido), o qual era diferente do corriqueiro. Além do desafio proposto: a construção de um livro infantil no coletivo. 


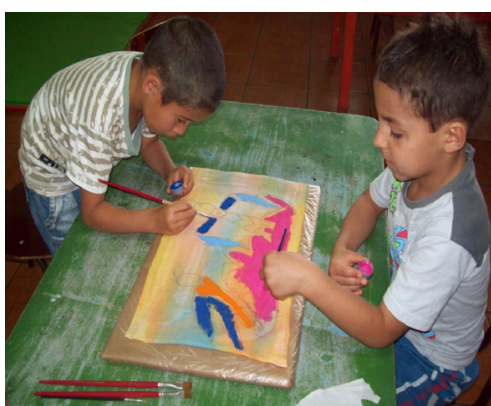

Figura 40

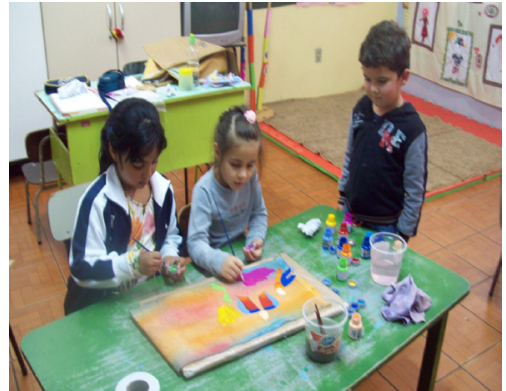

Figura 41

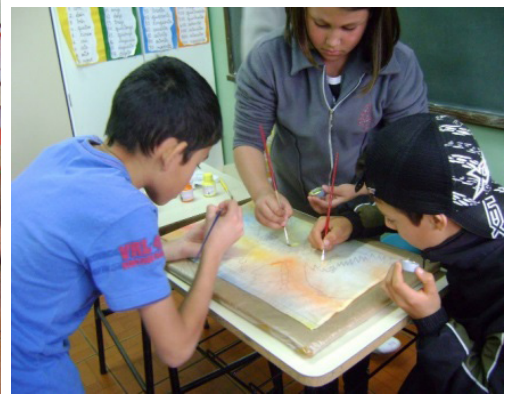

Figura 42

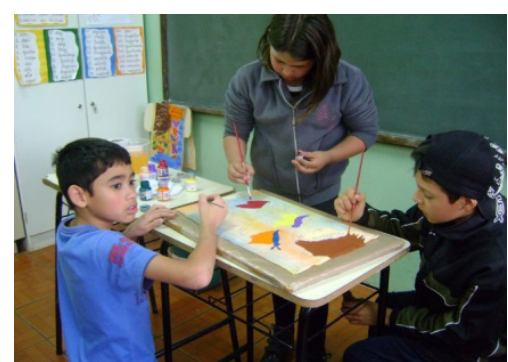

Figura 43

Figuras 40,41,42,43,44 - Pintura das imagens no livro

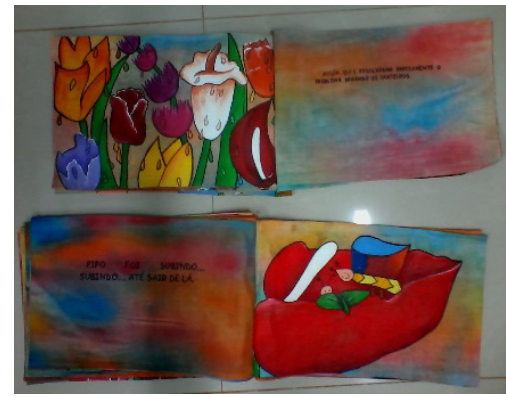

Figura 45

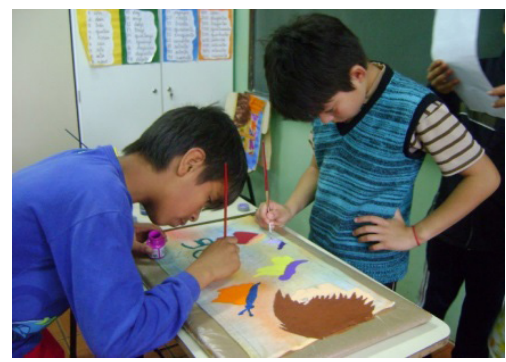

Figura 44

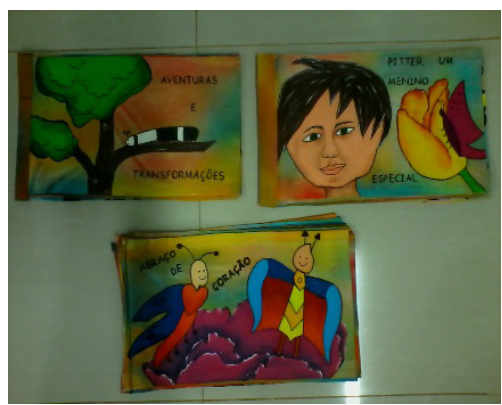

Figura 46

Figuras 45,46 - Livros prontos

Por conseguinte, outra atividade relacionada ao projeto foi o desafio de construir, com a família, borboletas tridimensionais, a partir de materiais alternativos e recicláveis. Pois, a sucata é um material de transformação que permite a liberdade para arriscar, buscar suas próprias soluções, dando maior oportunidade à ampliação de horizontes, resultando em um aprendizado de vida.

Benjamin (1984), Machado (1995), Waiss (1997), despertam para a importância das crianças criarem seus próprios brinquedos e sugerem situações de aprendizagem, que muitas vezes articulam recursos e capacidades afetivas, emocionais, sociais e cognitivas de cada criança.

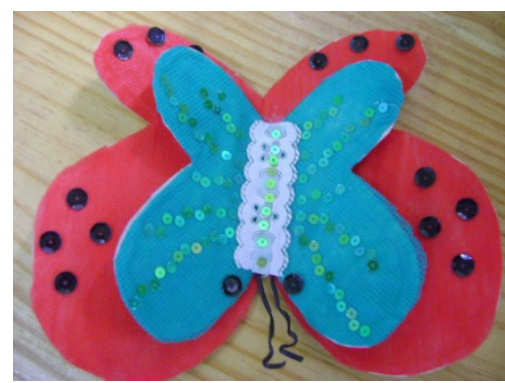

Figura 47

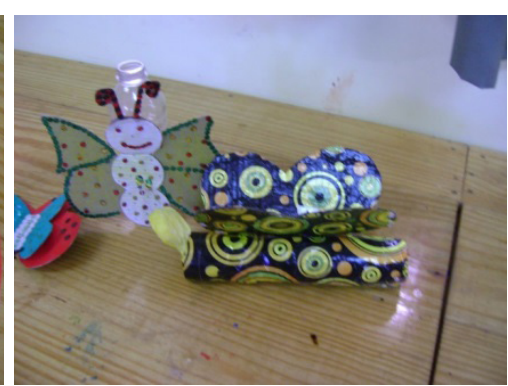

Figura 48

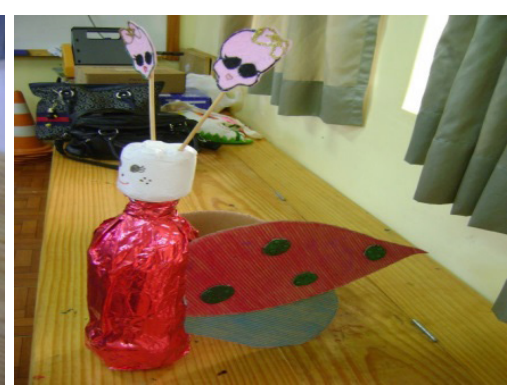

Figura 49

Figuras 47,48,49 - Borboleta construída com a família 
Assim, com o brinquedo-sucata, a criança exercita sua criatividade e estimula sua expressão ao confeccioná-lo. Consequentemente, resulta em um trabalho de transformação e reaproveitamento.

\section{CONSIDERAÇÕES FINAIS}

Portanto, com essa pesquisa, oportunizou-se às crianças problematizar a realidade, tentar compreendê-la e entender a importância das ações ecológicas e estéticas para si, para os outros e para o seu entorno. Além disso, para nós, educadores, o trabalho foi profícuo, pois como profissionais da educação, comprometemo-nos em fornecer subsídios ao projeto de forma interdisciplinar. Assim, oportunizar ao educando o envolvimento, a sensibilização e a criatividade em atividades significativas.

Destarte, quanto aos resultados esperados, verificou-se que os mesmos apresentaram-se positivos, pois houve uma proposta, a qual não fundamentou-se somente numa simples exposição de conteúdo, mas aos discentes disponibilizou-se instrumentos para que fluísse livremente a capacidade de observação e competências dos mesmos. Logo, não há como procrastinar a ideia do planejamento coletivo e a efetiva prática da interdisciplinaridade, consequentemente, abrindo-se perspectivas para novos casos de estudos.

\section{REFERÊNCIAS}

ALBINATTI, Maria Eugênia Castelo Branco. Artes visuais. Artes II. Belo Horizonte. 2009.

BAGNO, Marcos. Pesquisa na escola: o que é, como se faz. 18. Ed. São Paulo:Loyola, 1998.

BARBOSA, Ana Mae (Org.) Inquietações e Mudanças no Ensino da Arte, São Paulo, Editora Cortez,4a ed., 2008.

BENJAMIN, Walter. Reflexões sobre a criança, o brinquedo e a educação. Tradução de Marcus Vinícius Mazzari. São Paulo: Summus, 1984. (Novas buscas em educação, v. 17) Disponível em: http://www.partes.com. br/2013/07/05/experiencias-com-o-brinquedo-sucata-e-a-aprendizagem/.

BRASIL, Constituição Federal de 1988, (art.1º $2^{\circ}$, Lei Federal no 9.795, de 27/4/99).

BRITO, M. I. M. S. Das Lendas à História: A Busca da Identidade de um povo. Brasília, Dissertação-Mestrado em Desenvolvimento Sustentável. UnB, 2002

CAGNETI, Sueli de Souza. Que te Quero Livre. Rio de Janeiro: Nórdica, 1996.

CASTELS, Manuel. A sociedade em rede. 4.ed. São Paulo: Paz e Terra, 1999. Tradução Roneide Venâncio Majer. (A era da informação: economia, sociedade e cultura, v.1).

EINSTEIN, Albert, 1859 - 1955, Frases e Pensamentos. Disponível em: http://kdfrases.com, http://pensador. uol.com.br/autor/albert_einstein/

FREIRE, Paulo. Pedagogia da Autonomia, Saberes necessários à prática educativa. 10. ed. São Paulo: Paz e Terra, 1996.

Pedagogia da Indignação: Cartas pedagógicas e outros escritos. São Paulo: UNESP, 2000.

GUIMARÃES, Mauro. A dimensão ambiental na educação. 4 ed. Campinas (SP): Papirus, 2001.

HERNÁNDEZ, F. \& VENTURA, M. A organização do currículo por projetos de trabalho: o conhecimento é um caleidoscópio. Porto Alegre: ArtMed, 1998. 
LAGARTA E BORBOLETA. Disponível em: $h$ ttp://www.terrana.com.br/brasilanimal/LAGARTAS\%20E\%20BORBOLETAS/index.html

MACHADO, Marina Marcondes. O brinquedo-sucata e a criança: a importância do brincar - Atividades e materiais. $2^{a}$ ed. São Paulo: Editora Loyola, 1995(1995). Disponível em: http://www.partes.com.br/2013/07/05/ experiencias-com-o-brinquedo-sucata-e-a-aprendizagem/.

PEDRINI, Alexandre de Gusmão. Educação Ambiental: reflexões e práticas contemporâneas. Rio de Janeiro: Vozes, 1998.

PERRONE, Ercília; LARA, Maria Lúcia Martins Pinto. "Era uma vez...". In: SOUZA, Regina Célia; BORGES, Maria Fernanda S. Tognozzi (orgs.). A práxis na formação de educadores infantis. Rio de Janeiro: DP\&A, 2002.

TANNER, R. Thomas. Educação Ambiental. Editora Summus/Edusp, São Paulo, 1978.

WEISS, Luise. Brinquedos e engenhocas: atividade lúdica com sucata, $2^{a}$ ed., São Paulo, Editora Scipione, 1993. Disponível em:

http://www.avm.edu.br/docpdf/monografias_publicadas/posdistancia/37808.pdf 